\title{
Padrão de inserção da mulher negra no mercado de trabalho nordestino: notas para o período 2005-2014
}

\author{
Christiane Luci Bezerra Alves \\ Universidade Regional do Cariri - Crato - Ceará - Brasil \\ ORCID: https://orcid.org/0000-0001-5987-6814 \\ Jaqueline Kelândia Ferreira Alencar \\ Universidade Regional do Cariri - Crato - Ceará - Brasil \\ ORCID: http://orcid.org/0000-0002-4832-435X \\ Valéria Feitosa Pinheiro \\ Universidade Regional do Cariri - Crato - Ceará - Brasil \\ ORCID: http://orcid.org/0000-0002-1539-2751 \\ João Luís do Nascimento Mota \\ Universidade Regional do Cariri - Crato - Ceará - Brasil \\ ORCID: http://orcid.org/0000-0001-6172-5484
}

\section{Resumo}

Este ensaio se propõe ao entendimento de como tem sido processada a inserção da mulher negra no mercado de trabalho do Nordeste. Utiliza-se de metodologia descritiva, com base em revisão de literatura e na análise de dados secundários, que ocorre sob a perspectiva de raça e gênero, através da definição de quatro categorias: mulher negra (preta e parda), mulher não negra, homem negro (preto e pardo) e homem não negro. Os dados são provenientes dos microdados da Pesquisa Nacional por Amostra de Domicílios (PNAD), do Instituto Brasileiro de Geografia e Estatística (IBGE), para os anos de 2005 e 2014. Os resultados mostram que melhoria das condições econômicas e do mercado de trabalho experimentada pelo Brasil, especialmente nos anos 2000, ampliam as oportunidades reservadas às mulheres e se estendem, embora de forma diferenciada, condicionando um novo padrão de inserção das mulheres negras no mercado de trabalho. Todavia, apesar da melhoria inconteste de um conjunto de indicadores relativos à mulher negra, como o meselhor ritmo de crescimento da população ocupada, queda mais intensa do desemprego, maior variação da média de anos de estudo, além de ganhos significativos de participação em melhores faixas de escolaridade, a face do desemprego e da informalidade ainda é negra e feminina, o que demonstra o longo caminho a ser percorrido em busca de políticas mais inclusivas e focalizadas para a eliminação e não apenas suavização de disparidades e segregações.

Palavras-chave: Mulher negra. Mercado de trabalho. Nordeste. 


\section{Pattern of insertion of black women in the northeastern labor market: notes for the period 2005-2014}

\section{Abstract}

This essay aims to understand how the insertion of black women in the labor market in the Northeast has been processed. Descriptive methodology is used, based on literature review and secondary data analysis, which occurs from the perspective of race and gender, through the definition of four categories: black women (black and mixed race), non-black women, men black (black and brown) and non-black man. The data come from the microdata from the National Household Sample Survey (PNAD), from the Brazilian Institute of Geography and Statistics (IBGE), for the years 2005 and 2014. The results show that the improvement in economic conditions and the labor market experienced in Brazil, especially in the 2000s, they expand the opportunities reserved for women and extend, albeit in a different way, conditioning a new pattern of insertion of black women in the labor market. However, despite the indisputable improvement in a set of indicators related to black women, such as the best growth rate of the employed population, a more intense drop in unemployment, a greater variation in the average years of schooling, in addition to significant gains in participation in better bands In terms of schooling, the face of unemployment and informality is still black and female, which demonstrates the long way to go in search of more inclusive and focused policies for the elimination and not just smoothing disparities and segregations.

Keywords: Black woman. Labor market. Northeast

\section{Patrón de inserción de mujeres negras en el mercado laboral del noreste: notas para el período 2005-2014}

\section{Resumen}

Este ensayo tiene como objetivo comprender cómo se ha procesado la inserción de las mujeres negras en el mercado laboral en el noreste. Se utiliza una metodología descriptiva, basada en la revisión de la literatura y el análisis de datos secundarios, que ocurre desde la perspectiva de la raza y el género, a través de la definición de cuatro categorías: mujeres negras (raza negra y mixta), mujeres no negras, hombres hombre negro (negro y marrón) y no negro. Los datos provienen de los microdatos de la Encuesta Nacional de Muestra de Hogares (PNAD), del Instituto Brasileño de Geografía y Estadística (IBGE), para los años 2005 y 2014. Los resultados muestran que la mejora en las condiciones económicas y el mercado laboral experimentó En Brasil, especialmente en la década de 2000, amplían las oportunidades reservadas para las mujeres y amplían, aunque de manera diferente, condicionando un nuevo patrón de inserción de las mujeres negras en el mercado laboral. Sin embargo, a pesar de la mejora indiscutible en un conjunto de indicadores relacionados con las mujeres negras, como la mejor tasa de crecimiento de la población empleada, una caída más intensa del desempleo, una mayor variación en los años promedio de escolaridad, además de ganancias significativas en la participación en mejores bandas En términos de escolaridad, la cara del desempleo y la informalidad sigue siendo negra y femenina, lo que demuestra el largo camino por recorrer en busca de políticas más inclusivas y enfocadas para la eliminación y no solo para suavizar las disparidades y segregaciones.

Palabras clave: Mujer negra. Mercado de trabajo. Noreste. 


\section{Introdução}

Os movimentos que condicionam a estrutura recente do mercado de trabalho nordestino estão intrinsicamente associados às transformações estruturais experimentadas pela economia e sociedade brasileira nas últimas décadas e pelos reflexos dessas macro alterações em nível regional. As mudanças na ordem econômica e social, portanto, são sentidas de forma diferenciada pelos diferentes segmentos sociais, sendo fruto de particular interesse das Ciências Sociais. Nesse sentido, este ensaio se propõe ao entendimento de como tem sido processada a inserção da mulher negra no mercado de trabalho do Nordeste, região marcada por processos de exclusão e dependência que lhe conferiram lugar histórico de subordinação dentro da divisão interregional de trabalho no Brasil, sendo voltado a um segmento da sociedade também marcado por uma trajetória resistências em prol da superação das desigualdades racial e de gênero.

$\mathrm{Na}$ perspectiva da dinâmica regional, o conjunto de ajuste estruturais ocorridos na economia brasileira desde o esgotamento do processo de substituição importações (final da década de 1970) contribui para dinâmica de reacomodação na integração do Nordeste à economia nacional (DINIZ, 1995; GUIMARÃES NETO, 1994; FERREIRA LEMOS, 2000; PACHECO, 1999).

A crise fiscal sofrida pelo Estado brasileiro pôs fim a um longo ciclo no qual o Estado era o principal responsável pela dinamização do regime de acumulação, ao atuar de forma direta na provisão de insumos básicos e infraestrutura e através de políticas macroeconômicas e setoriais que viabilizaram a participação de capital privado nacional e estrangeiro na modelagem da matriz produtiva brasileira. Os elementos da crise dos anos 1980, onde se acumulam inflação explosiva, dívida externa crescente e dívida interna pública, além de uma economia que não acompanha as transformações em curso na economia mundial, vão expor a incapacidade do Estado de formular estratégias de desenvolvimento e de execução de políticas setoriais e regionais a partir de então (CARNEIRO; MODIANO, 2014).

O que se assiste, portanto, por toda a década de 1980, é o esvaziamento da política regional brasileira, ficando os estados nacionais entregues a sua própria sorte, em um ambiente macroeconômico adverso. Ao mesmo tempo, os movimentos de redemocratização que varreram o país com o fim do ciclo militar desenham um quadro de transformações sociais e novas demandas que serão consubstanciadas na Constituição Federal de 1998 e na renovação de parte das lideranças políticas, especialmente no Nordeste brasileiro. Sem uma estratégia global e integrada de desenvolvimento e diante de uma economia exposta à forte concorrência externa, fruto do ambiente pós abertura comercial e financeira do início da década de 1990, os espaços subnacionais serão forçados a traçar estratégias próprias de integração às economias nacional e internacional, onde se destacam a "guerra fiscal" e a busca pela atração de investimentos via incentivos fiscais e financeiros (ALVES; PAULO, 2014).

Passado um período de ajuste às transformações macroestruturais dos anos 1990, a região Nordeste será largamente beneficiada pelo ciclo recente de expansão de gastos públicos de natureza estrutural e pela ampliação de gastos sociais e dos programas de transferência de renda, especialmente dos anos 2000, que juntos contribuem para a sensível redução dos indicadores de pobreza e desigualdade, 
historicamente marcantes na região (RODRIGUES; ALVES, PAULO, 2012). Apesar dos avanços, mantém-se as assimetrias em padrões de desenvolvimento dentro da própria região. A persistência de vulnerabilidades históricas no âmbito social, especialmente no mercado de trabalho, relativo à qualidade das ocupações, mesmo reproduzindo características do padrão nacional, no Nordeste se manifestam através de postos de trabalho mais precários e com menor nível de remuneração, constituindo-se grande desafio para a proposição de políticas públicas inclusivas, especialmente para os segmentos mais vulneráveis, através da eliminação de múltiplas formas de segregação que atingem jovens, idosos e mulheres, além da discriminação pela raça.

Relativo à perspectiva de gênero, Leone e Baltar (2008, p. 234) já chamavam atenção que qualquer análise do mercado de trabalho no Brasil "deve levar em conta a progressiva participação das mulheres na atividade econômica", fenômeno em curso desde as últimas décadas do século XX. Contribuem para isso, fatores estruturais, como a facilidade proporcionada pelas novas tecnologias, que permitem, inclusive, a inserção em ocupações tipicamente masculinas; a queda na taxa de fecundidade e o aumento da escolaridade feminina; adicionalmente, os movimentos de desestruturação da economia em ciclos recentes e os ajustes recessivos forçaram as mulheres a buscarem uma renda complementar para a família. Destacam-se as transformações societárias recentes, os movimentos próempoderamento feminino, as lutas conta discriminação por gênero e em prol de políticas afirmativas ${ }^{1}$. Com papel relevante nesse processo, ressaltam-se, ainda, as mudanças no perfil da família brasileira, com a diminuição no número de filhos, crescimento da quantidade de domicílios com um único membro e ampliação do número de famílias chefiadas por mulheres (BRUSCHINI; LOMBARDI, 2011; HIRATA, 2015; LEONI; BALTAR, 2008).

As vulnerabilidades que marcam o mercado de trabalho no Brasil são singularmente sentidas quando se considera a inserção da mulher negra no mundo do trabalho. A herança da tradição escravocrata e patriarcalista no conjunto da sociedade brasileira reservou historicamente às mulheres negras a inclusão tardia, a deficiência na formação educacional e profissional, além do empobrecimento dessa população, onde dominam ocupações precárias e mal remuneradas.

Nessa perspectiva, esse ensaio se propõe a entender o padrão recente de inserção da mulher negra no mercado de trabalho nordestino, para os anos de 2005 e 2014. Consideram-se, para isso, a identificação de como, onde se inserem e qual a qualidade dos postos de trabalho ocupados. Utiliza-se de metodologia descritiva, com base em revisão de literatura e na análise de dados secundários, provenientes dos microdados da Pesquisa Nacional por Amostra de Domicílios (PNAD), do Instituto Brasileiro de Geografia e Estatística (IBGE). Os movimentos que condicionam a performance do emprego regional reproduzem basicamente os movimentos ocorridos em nível nacional. Assim, a conjuntura econômica, bem

\footnotetext{
${ }^{1}$ As ações afirmativas são expressas por políticas públicas ou privadas que visam eliminar todo tipo de discriminação. Mediante essas políticas, possibilita-se, para um determinado grupo menos favorecido, vantagens não aplicáveis a outros segmentos das populações. Como resultado, as ações afirmativas são mecanismos voltados para o grupo da população em desvantagem social, que têm em vista a promoção da igualdade material ou substancial (GARCIA, 2012).
} 
como a dinâmica do mercado de trabalho associada a tal conjuntura, entre 2005 e 2014, serão abordadas na seção 2 deste trabalho. Um quadro histórico de apreensão da mulher negra na sociedade e no mercado de trabalho no Brasil será discutido na seção 3; na última seção de análise, o entendimento do mercado de trabalho ocorrerá na perspectiva de raça e gênero, através da análise das categorias mulher negra (preta e parda), mulher não negra, homem negro (preto e pardo) e homem não negro.

\section{Conjuntura e dinâmica do mercado de trabalho recente no Brasil}

A dinâmica recente do mercado de trabalho no Brasil apresenta um 'ponto de inflexão' na primeira década dos anos 2000, considerando o cenário de limitações experimentado pela economia doméstica nos anos de 1980 e 1990. A desestruturação do trabalho nestas décadas é condicionada: i) pela política macroeconômica adversa e as consequentes restrições no nível de atividade econômica, como durante os constrangimentos impostos pela ortodoxia do início das décadas de 1980 (Choque Ortodoxo) e 1990 (Plano Color); ii) pelo cenário de incertezas imposto pelas crises externas, condicionantes de ajustes monetários e cambiais também penosos ao crescimento e à inserção externa da economia brasileira; iii) pelo ajuste defensivo ${ }^{2}$ engendrado pela economia doméstica frente às mudanças estruturais de orientação neoliberal impulsionadas nos governos Collor e Fernando Henrique Cardoso (FHC) (especialmente através da abertura comercial e financeira, programa de privatizações e integração passiva ao processo de globalização mundial), que força intenso movimento de reestruturação produtiva, com caráter mais estrutural.

Os resultados são sentidos de forma não negligenciável na geração de postos de trabalho e na qualidade dos mesmos. Ao peso do desemprego estrutural são somadas as restrições dos mecanismos de desregulação do trabalho no Brasil. Além disso, a criação de empregos mostra-se especialmente elástica à fragilidade na dinâmica setorial do país, que no período encontra-se mais vulnerável pelo grau de internacionalização da economia e limitada pelos condicionantes externos. Particularmente nos anos 1990, experimenta-se aumento do desemprego aberto, do grau de informalização, do número de empregados sem carteira ou por conta própria (NERI; CAMARGO; REIS, 2000; COUTINHO; BALTAR; CAMARGO, 1999). O processo de desindustrialização, em curso desde a década anterior, contribui para a geração de postos de trabalho mais precários, em setores onde é maior a rotatividade, as subcontratações, os empregos temporários e menos qualificados, como os segmentos menos dinâmicos do setor de serviços.

A partir de 2003, o mercado de trabalho passa a responder às alterações no modo de regulação nacional, que após os movimentos mais explícitos de desregulação do Estado e dos mercados dos anos 1990, desenha um novo protagonismo estatal que tenta equacionar estabilidade e controle macroeconômico, com retomada de investimentos públicos e proteção social.

2 Esses processos envolvem a reestruturação produtiva, incorporação de novos padrões tecnológicos e novas técnicas de gestão, baseadas na flexibilização, desverticalização, especialização, planejamento estratégico, terceirização etc. 
Particularmente em 2003, o mercado de trabalho encontra-se sob subjunção determinada pela ortodoxia do início do governo Lula, que aprimora elementos do tripé macroeconômico da segunda fase do governo FHC (1999-2002), através do regime de metas inflacionárias, câmbio flutuante e superávit primário (no melhor estilo "stop and go") e resultam num crescimento do Produto Interno Bruto (PIB) pouco expressivo (1,14\%) e na contração da taxa de crescimento da renda per capta $(0,17 \%)$. Inicia-se, nesse momento, uma trajetória consistente, quase ininterrupta de queda do desemprego, que de uma taxa de $12,3 \%$, em 2003 , chega a atingir $4,8 \%$, em 2014 (IBGE, 2019).

O ciclo expansivo, alimentado por uma política mais flexível de gastos, crédito e pela tendência de reversão nas taxas de juros, soma-se a uma política de inclusão que envolve elevação e maior amplitude dos programas de transferência de renda e uma política de valorização contínua do salário mínimo ${ }^{3}$. Os resultados são sentidos no desempenho da economia, a qual cresce a 4,8\% a.a., entre 2004 e 2008 e na melhoria contínua do rendimento médio, que cresce a 10,4\% no período (IBGE, 2019). Ainda constata-se expansão dos investimentos público e privado, além de ganhos de produtividade, num cenário onde permanece o controle da inflação nas metas estabelecidas pelo Bacen, acompanhado pelo acúmulo de reservas internacionais (BARBOSA; SOUZA, 2010). O desempenho da economia brasileira encontra-se atrelado, ainda, às tendências de crescimento da economia mundial, expansão da liquidez e valorização das commodities agrominerais. Vale ressaltar um movimento de ruptura nas estratégias de política externa, através de uma atuação mais independente e diversificada nas relações comerciais brasileiras, onde também se destaca a cooperação com vizinhos regionais e outras potências médias, atribuindo maior interesse nas relações do eixo Sul-Sul (OLIVEIRA, 2014).

O mercado de trabalho foi beneficiado, portanto, pela recuperação da atividade econômica, que em razão do aumento na capacidade produtiva, pode ampliar o número de contratações formais. Por sua vez, a recuperação do poder de compra do salário mínimo, a redução das desigualdades sociais, a instituição do regime tributário simplificado que dinamiza o segmento de micro e pequenas empresas - Sistema Integrado de Pagamento de Impostos e Contribuições das Microempresas e das Empresas de Pequeno Porte (SIMPLES) - e a criação da política de formalização do microempreendedor individual (MEI) estimularam o aumento da produção e criaram componentes essenciais para o crescimento do país no período pré-crise.

Nesse cenário, destaca-se:

um novo desenho da política social no Brasil, caracterizando-se por elementos de caráter mais universal e mecanismos mais estruturais para o combate à pobreza, com a focalização e ampliação de programas de transferência de renda, expansão da cobertura da previdência rural, ampliação da política de microcrédito, programas especiais de estímulo à agricultura familiar, entre outros, os quais terão importantes efeitos na potencialização da demanda, dinamização da economia popular e, consequentemente, na promoção de emprego e formalização do mercado de trabalho (ALVES et al., 2018, p. 137).

\footnotetext{
${ }^{3} \mathrm{O}$ ano de 2007 marcou o início da recuperação do salário mínimo, intensificado com o Projeto de Lei $\mathrm{n}^{\circ} 1$ de 2007, que estabelece as diretrizes para política de valorização salarial de 2008 a 2023.
} 
A crise financeira de 2008 propaga um clima de incertezas, onde se adiam as decisões de investimento e consumo, resultando numa desaceleração da atividade econômica. O ajuste se estende à preferência pela liquidez e contração do crédito interno e à orientação externa da economia, quando são afetadas demanda externa e preço das commodities no mercado mundial, com resultados negativos nas contas externas (ARAUJO; GENTIL, 2011).

Contudo, a resposta imediata, através de uma política anticíclica do tipo keynesiana, amortece os efeitos da crise externa sobre a economia nacional. No campo fiscal, registram-se: redução das alíquotas do Imposto sobre Produtos Industrializados (IPI), para os setores automobilísticos e eletrodomésticos de linha branca e moveleiro; redução do Imposto de Renda de Pessoa Física (IRPF), além da criação do Regime Especial de Tributação (RET), que reduz largamente o imposto sobre imóveis. Ressalta-se a manutenção e ampliação das modalidades de transferências de renda, além do anúncio da redução na meta do superávit primário, em março de 2009. No campo monetário, sobressaem-se as reduções no depósito compulsório e aumento real da liquidez dos bancos, através da disponibilidade de recursos para compra de carteiras de crédito no mercado bancário por parte dos bancos públicos (ARAUJO; GENTIL, 2011). O arcabouço macroeconômico engendrado desempenha, portanto, um papel importante na sustentação da demanda interna. Nesse sentido, apesar da contração do nível de atividade ser sentida em 2009, correspondente a 0,13\%, o nível de desemprego aumenta em 0,2 pontos percentuais e a recuperação robusta da economia em 2010 (crescimento do PIB de 7,53\%), reflete-se na queda do desemprego, que atinge $6,73 \%$ neste ano (IBGE, 2019).

Não obstante o arrefecimento no ritmo de crescimento entre 2011 e 2014, $2,35 \%$ a.a., em meio a orientação mais ortodoxa da política macroeconômica do primeiro governo de Dilma $^{4}$ (reversão da tendência de queda dos juros, controle de gastos e revisão das metas de superávit primário), o mercado de trabalho segue ampliando contratações, aumentando a formalização e reduzindo o desemprego (que atinge seu menor nível em 2014, com taxa de 4,82\%) (IBGE, 2019).

\section{Aspectos históricos e institucionais da mulher negra na sociedade e no mercado de trabalho}

O desenvolvimento capitalista mundial teve como base de sustentação a escravidão afro-americana moderna. Classes dominantes, não só do Brasil como de outros países, enriqueceram as custas da exploração do trabalho do negro escravizado, que durante três séculos produziu a grande maioria dos artigos tropicais vendidos na Europa. Ao longo desses séculos, a compra e venda de africanos contribuiu para que a Europa seguisse seu processo de dominação econômica e social frente à civilização ocidental (MUNANGA; GOMES, 2006).

\footnotetext{
${ }^{4}$ A principal orientação de política econômica fica em parte condicionada pelo agravamento da crise internacional na zona do euro entre 2011 e 2014, o que provocou contração na média de crescimento mundial, que reduziu de 5,2\%, em 2010, para 2,9\%, ainda em 2013 (GENTIL; HERMANN, 2017).
} 
Inserida nesse contexto, encontrava-se a mulher negra escravizada, que conforme destaca Davis (2016), para seus senhores era destituída de gênero, quando se tratava da exploração de sua força produtiva, ou seja, as mulheres eram exploradas da mesma forma que os homens escravizados. No entanto, havia formas de opressões usadas pelos senhores e feitores que atingiam especialmente as mulheres, como a violência sexual e outros castigos brutais. "O estupro, na verdade, era uma expressão ostensiva do domínio econômico do proprietário e do controle do feitor sobre as mulheres negras na condição de trabalhadoras" (DAVIS, 2016, p. 26). Mesmo diante de toda opressão a qual foram sujeitadas, a história dessas mulheres é de resistência ao sistema escravista. Somada a outros fatores, a resistência da população negra ao sistema escravocrata foi um fator relevante a ser considerado para o fim da escravidão.

Com a assinatura da Lei Áurea ${ }^{5}$, a população negra oficialmente conquistou sua liberdade, entretanto, ainda continuou sendo excluída socialmente. Devido a situação em que essa população vivia, negras e negros eram tidos como incapazes, ociosos e acomodados em relação aos imigrantes europeus que vieram para trabalhar no país. Em consequência, às negras era reservado o trabalho doméstico, expressão que refletia a situação de 'domesticada' da mulher no período escravocrata. Ainda que legalmente considerados cidadãos, a população negra, na prática, era excluída e impossibilitada de usufruir de benefícios sociais, carregava o estigma da cor da sua pele, sendo discriminada pelo que isso simbolizava (NOGUEIRA, 1998).

Segundo Nogueira (1998), percebendo-se que a abolição da escravatura não foi garantia de inserção dos negros e negras como trabalhadores no mercado, ao contrário, na medida em que foram sendo abandonados por seus antigos senhores, essa parcela da população foi sendo progressivamente considerada um peso para a sociedade. Diante desse contexto, o que restou aos negros foi viver como marginais, mendigos e prostitutas, refletindo na visão atual ainda estereotipada, equivocada e segregacionista da sociedade que associa a população negra ao conceito atual de marginalização.

Para os afro-brasileiros, à desigualdade socioeconômica soma-se a segregação, especialmente no mercado de trabalho, sendo reproduzido "o fenômeno da discriminação ao acesso as oportunidades do mercado de trabalho, principalmente no que se refere a algumas atividades laborais e funções hierárquicas" (MARTINS, 2000, p. 414).

Assim, fica evidente que a estrutura social, econômica e política brasileira teve como base um procedimento de exclusão por uma elite fundamentada em convenções patriarcais e racistas que conduziram preceitos essenciais para a criação de leis. Isso mostra que as vulnerabilidades das mulheres negras na sociedade são decorrentes do período escravista e do pós-escravista, onde o trabalho escravo foi substituído pelo assalariado (VIEIRA, 2017).

\footnotetext{
${ }^{5}$ Lei Imperial $\mathrm{n}^{\circ} 3.353$, sancionada em 13 de maio de 1888 , pela Princesa Isabel. Foi precedida pela Lei $\mathrm{n}^{\circ} 581$ (Eusébio de Queirós), de 1850, que proibiu a entrada de africanos escravos no Brasil; pela Lei $\mathrm{n}^{\circ} 2.040$ (Ventre Livre), de 1871, que concedeu alforria a todas as crianças nascidas de mulheres escravizadas; e pela Lei $n^{\circ} 3.270$, de 1885 (Sexagenários), que libertava os escravos com mais de 60 anos de idade.
} 
A manutenção dessas posições sociais desfavoráveis não permaneceu exclusivamente como um legado escravista, pois é reproduzida na prática das relações sociais do país, determinadas pela tripla discriminação de classe, raça e sexo (VIEIRA, 2017). Essa estrutura social determina que "uma posição inferior na relação ampla entre brancos/negros homem/mulher deve corresponder uma posição inferior no trabalho onde o lugar de um jamais seja ocupado pelo outro" (BENTO, 1995, p. 7).

Destaca-se que nas grandes cidades, na transição do século XIX para o XX, o trabalho doméstico foi uma das principais atividades que garantiram a entrada de muitas mulheres negras no sistema produtivo, sendo, em muitos casos, o único meio de acesso a um posto de trabalho. Apesar das transformações ocorridas na economia e sociedade brasileira ao longo do século $\mathrm{XX}$, o trabalho doméstico continuou a ser essencialmente feminino e negro. Este tipo de trabalho foi historicamente subvalorizado por boa parte da sociedade, definindo-se pelos menores salários e altas cargas horárias, além da falta de contribuição à previdência e de elevados índices contratuais menos formais (DIEESE, 2005; PEREIRA, 2011).

Para Trippia e Baracat (2014), portanto, as vulnerabilidades a que estão submetidas as mulheres negras podem ser observadas quando se percebe que as oportunidades de acesso ao emprego dão-se de maneira desigual, hierarquicamente inferiores e com baixa remuneração. Acrescenta-se a inserção tardia no sistema de ensino, a evasão escolar e baixa escolaridade de modo geral, limitando o acesso a melhores oportunidades de trabalho.

As transformações econômicas que dinamizam a economia brasileira, acompanhando o rápido processo de industrialização após a década de 1950, especialmente o "boom" de crescimento e urbanização experimentados especialmente nos anos de 1970, condicionam, em larga medida, a inserção da mulher no mercado de trabalho brasileiro. Porém, os postos de trabalho criados, intimamente ligados à dinâmica industrial latente, determinam o recorte de raça e as mulheres negras, com menor escolaridade e qualificação, não são beneficiadas igualmente pela nova dinâmica ocupacional, sendo-lhes reservados postos mais ligados a prestação de serviços, acompanhando o crescimento da rede de serviços subjacente ao crescimento industrial.

As últimas décadas do século XX e primeira década do século XXI são marcadas por cenários de crises econômicas, implementação de reformas estruturais de orientação neoliberal, reestruturação produtiva e sensíveis alterações nas relações de trabalho, o que impõe ajustes tanto na oferta, quanto na demanda de trabalho no Brasil. Particularmente, a melhoria dos indicadores experimentada nos anos 2000 é estendida ao conjunto de mulheres, embora os grupos mais vulneráveis mantenham certas particularidades, como o de mulheres negras. Embora melhorem os níveis de formalização, o fenômeno do desemprego e de postos e salários precários neste segmento constituem largos desafios para uma sociedade que demanda padrões mais igualitários e empregos decentes para camadas da populações historicamente penalisadas pela lógica dos modelos de exploração e de acumulação do capital.

Nesse mesmo período, sobressaem-se um conjunto de alterações e novas proposições do arranjo institucional e ordenação jurídica, que envolvem políticas repressivas e um conjunto de ações afirmativas e valorativas que criam novas 
condições para um novo tratamento da sociedade brasileira no enfrentamento das segregações por raça no Brasil.

Na Constituição Federal, de 1988, destacam-se o princípio de garantia "à dignidade da pessoa humana" (item III, do artigo $1^{\circ}$ ) e o objetivo fundamental do Estado de "promover o bem estar de todos sem preconceitos de origem, raças, sexo, cor, idade e quaisquer outras formas de discriminação" (item IV, do artigo $3^{\circ}$ ) (BRASIL, 1988). Como marco legal, ainda, ressaltam-se: o Estatuto de Igualdade Racial (BRASIL, 2010), que permite, por exemplo a adesão do Brasil aos compromisso assumidos junto à Organização Internacional do Trabalho - OIT, no que trata da discriminação no emprego e na profissão, especialmente à mulher no mercado de trabalho; um conjunto de leis anti-racistas, como as que tornam a prática do racismo crime inafiançável e imprescritível, além da tipificação do crime de injúria racial (BRASIL, 1989; 1997).

Nas ações afirmativas, o destaque fica por conta das leis que garantem o ensino de História e Cultura Afro-Brasileira no ensino público e privado; o Programa Universidade para Todos - PROUNI, que oferece bolsas, a alunos pobres, indígenas e negros e a Lei de Cotas para Universidades Públicas, que possibilita o acesso a alunos pobres, indígenas e negros (BRASIL, 2003; 2005; 2012).

\section{Onde e como se insere a mulher negra no mercado de trabalho nordestino}

As últimas décadas do século XX revelam que o país tem experimentado um intenso processo de transição demográfica, expresso através do rápido declínio dos níveis de fecundidade e da redução dos índices de mortalidade, diminuindo, portanto, a razão de dependência e contribuindo para a mudança na estrutura etária da população, com crescimento do peso relativo da população idosa. Esses mecanismos são sentidos na ampliação da população em idade ativa (PIA), que implica no aumento da participação de indivíduos em idade produtiva. Esse fenômeno gera o chamado "bônus demográfico", que representa uma "janela de oportunidade" decorrente da mudança da estrutura etária da pirâmide populacional (ALVES, 2008; BRITO, 2008). O aproveitamento do "bônus demográfico" dependerá se o crescimento da economia e as mudanças na regulação do mercado criarem oportunidades concretas de inserção da população no mercado de trabalho.

Considerando o período em análise, o Nordeste, para todas as categorias, repete o comportamento brasileiro, com a ampliação da PIA (Tabela 1). Porém, relativo à População Economicamente Ativa (PEA), o aumento é registrado para as categorias mulher negra e homem negro, constituindo-se forças relevantes no crescimento da força de trabalho da região. O ritmo de crescimento da PIA e PEA, por conseguinte, faz com que a taxa de participação, indicativo da dimensão do mercado de trabalho (oferta de trabalho) se reduza em todos os casos analisados.

De maneira geral, tanto no Nordeste como no Brasil, entre 2005 e 2014, a população ocupada evolui positivamente, embora no Nordeste cresça em ritmo mais lento (0,9\% a.a., para Nordeste, e 1,41\% a.a., para o Brasil). O melhor ritmo de crescimento anual ocorre entre as mulheres negras ( $1,59 \%$ a.a.). Isso reflete na evolução positiva da taxa de ocupação, que traduz a demanda por trabalho, com exceção apenas da categoria homem não negro. 
Tabela 1 - Nordeste - Condição de atividade/ocupação no trabalho principal, taxas de participação, ocupação e desemprego - mulheres e homens, negros e não

\begin{tabular}{|c|c|c|c|c|c|c|c|c|}
\hline \multicolumn{9}{|c|}{ negros - 2005/2014 } \\
\hline & \multicolumn{4}{|c|}{2005} & \multicolumn{4}{|c|}{2014} \\
\hline & \multicolumn{2}{|c|}{ Mulher } & \multicolumn{2}{|c|}{ Homem } & \multicolumn{2}{|c|}{ Mulher } & \multicolumn{2}{|c|}{ Homem } \\
\hline & Negra & $\begin{array}{c}\text { Não } \\
\text { negra }\end{array}$ & Negro & $\begin{array}{c}\text { Não } \\
\text { negro }\end{array}$ & Negra & $\begin{array}{c}\text { Não } \\
\text { negra }\end{array}$ & Negro & $\begin{array}{c}\text { Não } \\
\text { negro }\end{array}$ \\
\hline PIA & 15.005 .312 & 6.638 .181 & 14.661 .797 & 5.729 .338 & 18.017 .096 & 6.992 .742 & 16.922 .636 & 5.926 .993 \\
\hline PEA & 7.737 .125 & 3.305 .932 & 10.792 .938 & 4.148 .716 & 8.726 .405 & 3.267 .944 & 11.760 .762 & 4.083 .996 \\
\hline $\mathrm{PO}$ & 6.772 .959 & 2.959 .398 & 10.016 .843 & 3.894 .639 & 7.787 .400 & 2.971 .531 & 11.031 .589 & 3.830 .257 \\
\hline PD & 964.166 & 346.534 & 776.095 & 254.077 & 939.005 & 296.413 & 729.173 & 253.739 \\
\hline $\begin{array}{l}\text { Tx partic. } \\
\text { (PEA/PIA) }\end{array}$ & 51,56 & 49,80 & 73,61 & 72,41 & 48,43 & 46,73 & 69,50 & 68,91 \\
\hline $\begin{array}{l}\text { Tx ocup. } \\
\text { (PO/PEA) }\end{array}$ & 87,54 & 89,52 & 92,81 & 93,88 & 89,24 & 90,93 & 93,80 & 93,79 \\
\hline $\begin{array}{l}\text { Tx desem. } \\
\text { (PD/PEA) }\end{array}$ & 12,46 & 10,48 & 7,19 & 6,12 & 10,76 & 9,07 & 6,20 & 6,21 \\
\hline
\end{tabular}

Fonte: elaborada pelos autores a partir das PNADs de 2005 e 2014.

Acompanhando a boa performance da economia brasileira, associadas à queda expressiva na população desocupada, as taxas de desemprego também são reduzidas, com exceção de homens não negros, permanecendo em 2014 em patamar muito próximo ao de 2005. A queda mais intensa no desemprego é experimentada pelas mulheres negras. Porém, esse grupo continua a ser o mais prejudicado pelo desemprego, atingindo uma taxa de 10,76\% em 2014, 4,6 pontos percentuais acima de homens negros e não negros. Esse dado revela a segregação por gênero ainda presente em larga escala na sociedade e economia brasileira, estendida mais intensamente às mulheres negras.

Contudo, a ampliação das oportunidades de inserção da mulher negra no mercado de trabalho só contribuirá para a reversão de suas vulnerabilidades históricas a depender da qualidade de suas ocupações.

A análise da concentração de trabalhadores e trabalhadoras por setor de atividade está exposta na Tabela 2. Os dados de 2005 revelam que, independente da categoria, a mão de obra concentra-se majoritariamente em atividade agrícolas, fruto de uma herança histórica da estrutura nordestina largamente dependente deste setor e de outras atividades tradicionais, embora a tabela não consiga captar a perda dessa participação, em curso em período anterior a 2005. A dinâmica dos anos em estudo mostra que o setor agrícola perde expressiva quantidade de trabalhadores, principalmente nas categorias mulher negra e homem negro, com redução de 9,41 pontos percentuais e 12,89 p.p., respectivamente.

Todavia, se somados setor agrícola e comércio e reparação, a concentração de trabalhadores ainda se dá em postos com maior perfil degradante, menores remunerações e no caso do último setor, maior rotatividade, sendo caracterizado por um grande exército de reserva, já que demandam, agora no caso dos dois setores, menores padrões de escolaridade.

A indústria de transformação, que liderou por décadas a geração de postos de trabalho com menor nível de precarização, perde participação em todas as categorias, sendo que as mulheres negras ainda tem uma dificuldade maior de 
ocupação nesse segmento. As retrações, conforme categoria, correspondem a: 1,97 p.p (mulher negra); 0,99 p.p. (mulher não negra); 0,63 p.p. (homem negro) e 0,28 (homem não negro).

O setor de construção ainda é majoritariamente composto por mão de obra masculina, mas chama atenção o ganho expressivo de trabalhadores concentrados nesse segmento (homens negros e não negros), que reflete o movimento geral de recuperação da indústria de construção no período, contribuindo para isso: a ampliação de investimentos públicos em infraestrutura (através do Plano de Aceleração do Crescimento (PAC)) e onde o Nordeste se beneficiará de uma série de inversões; a retomada do crédito imobiliário e condições especiais para diferentes faixas de renda da população, com destaque para o Programa Minha Casa, Minha Vida; e a maior integração entre programas federais de estímulo ao setor com políticas estaduais, por certo mais fragmentadas, mas que aquecem o mercado da construção de forma geral (ALVES, 2017).

Chama atenção a concentração das mulheres em atividade de ensino, saúde e serviços sociais, que aumenta no período analisado, o que pode representar uma melhoria de qualidade nas ocupações no longo prazo, podendo e devendo ser potencializada através de políticas públicas focalizadas, integradas e afirmativas.

Tabela 2 - Nordeste - Ocupação de mulheres e homens, negros e não negros, segundo setor de atividade $-2005 / 2014$

\begin{tabular}{|c|c|c|c|c|c|c|c|c|}
\hline \multirow{3}{*}{ Posição na ocupação } & \multicolumn{4}{|c|}{2005} & \multicolumn{4}{|c|}{2014} \\
\hline & \multicolumn{2}{|c|}{ Mulher } & \multicolumn{2}{|c|}{ Homem } & \multicolumn{2}{|c|}{ Mulher } & \multicolumn{2}{|c|}{ Homem } \\
\hline & Negra & $\begin{array}{l}\text { Não } \\
\text { negra }\end{array}$ & Negro & $\begin{array}{l}\text { Não } \\
\text { negro }\end{array}$ & Negra & $\begin{array}{l}\text { Não } \\
\text { negra }\end{array}$ & Negro & $\begin{array}{l}\text { Não } \\
\text { negro }\end{array}$ \\
\hline Agrícola & 31,44 & 22,70 & 43,37 & 35,05 & 22,03 & 15,65 & 30,47 & 25,77 \\
\hline $\begin{array}{l}\text { Outras atividades } \\
\text { industriais }\end{array}$ & 0,19 & 0,19 & 0,95 & 1,34 & 0,17 & 0,38 & 0,96 & 1,14 \\
\hline $\begin{array}{l}\text { Indústria de } \\
\text { transformação }\end{array}$ & 9,75 & 9,98 & 8,48 & 8,51 & 7,78 & 9,00 & 7,85 & 8,23 \\
\hline Construção & 0,22 & 0,39 & 9,57 & 7,26 & 0,51 & 0,53 & 16,24 & 12,05 \\
\hline Comércio e reparação & 14,07 & 18,70 & 14,82 & 19,47 & 16,38 & 18,72 & 17,23 & 19,81 \\
\hline $\begin{array}{l}\text { Alojamento e } \\
\text { alimentação }\end{array}$ & 3,97 & 3,95 & 2,71 & 3,04 & 6,40 & 6,30 & 3,10 & 3,90 \\
\hline $\begin{array}{l}\text { Transporte, } \\
\text { armazenagem e } \\
\text { comunicação }\end{array}$ & 0,62 & 0,95 & 5,10 & 6,10 & 0,83 & 0,99 & 6,92 & 7,89 \\
\hline Administração pública & 3,69 & 6,05 & 4,50 & 5,95 & 4,69 & 6,63 & 4,98 & 5,92 \\
\hline $\begin{array}{l}\text { Educação, saúde e } \\
\text { serviços sociais }\end{array}$ & 13,48 & 17,42 & 2,50 & 3,95 & 16,32 & 20,85 & 3,84 & 4,98 \\
\hline Serviços domésticos & 16,04 & 10,88 & 0,89 & 0,65 & 14,82 & 9,50 & 0,70 & 0,55 \\
\hline $\begin{array}{l}\text { Outros serviços } \\
\text { coletivos, sociais e } \\
\text { pessoais }\end{array}$ & 4,14 & 4,29 & 2,34 & 2,43 & 5,48 & 5,38 & 2,31 & 2,84 \\
\hline Outras atividades & 2,35 & 4,46 & 4,34 & 5,83 & 4,54 & 6,06 & 5,25 & 6,87 \\
\hline $\begin{array}{l}\text { Atividades mal definidas } \\
\text { ou não-declaradas }\end{array}$ & 0,05 & 0,03 & 0,44 & 0,41 & 0,04 & 0,01 & 0,15 & 0,03 \\
\hline Total & 100 & 100 & 100 & 100 & 100 & 100 & 100 & 100 \\
\hline
\end{tabular}

Fonte: elaborada pelos autores a partir das PNADs de 2005 e 2014. 
Cabe destaque a concentração elevada de mulheres em serviços domésticos, especialmente as negras, característica histórica da segregação imposta pelo mercado de trabalho a esse segmento da população, cujas raízes remontam à tradição escravocrata, patriarcalista e aos ciclos posteriores de desvalorização social nos quais está imersa a população negra no Brasil. Em 2005, 16,04\% das mulheres negras desenvolviam serviços domésticos, percentual que apresenta leve redução para 14,82\%, em 2014. Isso impõe à parte expressiva destas mulheres, condições gerais de trabalho especialmente precarizadas. De modo geral, o serviço doméstico é marcado pelo seu maior nível de inseguridade, constatando-se que, em muitos casos, tais trabalhadores encontram-se na informalidade, sem carteira de trabalho e, consequentemente, legalmente desamparados (LOPES; LUCILVO FILHO; LIMA, 2018). As conquistas recentes no âmbito da legislação trabalhista brasileira, com a aprovação da "Proposta de Emenda à Constituição (PEC) das Domésticas", por meio da Emenda Constitucional $n^{\circ} 72 / 2013$, além da Lei Complementar $n^{\circ}$ 150/2015, ampliam os direitos destes trabalhadores, contribuindo para redução de distorções históricas, por vezes desumanas e inóspitas, criando um ambiente de trabalho mais dignificante. Todavia, os efeitos das mudanças institucionais nesse campo ainda não puderam ser captados, pela limitação imposta pelo período de análise.

Um indicador positivo do melhoramento das condições do mercado de trabalho recente no Brasil é a maior tendência de formalização, fenômeno que se repete no Nordeste brasileiro em todos os grupos analisados, quando aumentam os percentuais de trabalhadores com carteira assinada. Apesar da diminuição da informalidade das mulheres negras em 10,62 p.p., 55,02\% destas trabalhadoras ainda estão, em 2014, alijadas de rendimentos através de carteira assinada (Tabela 3).

Tabela 3 - Nordeste - Ocupação de mulheres e homens, negros e não negros, segundo $-2005 / 2014$

\begin{tabular}{l|c|c|c|c|c|c|c|c}
\hline \multirow{2}{*}{$\begin{array}{c}\text { Situação } \\
\text { ocupacional }\end{array}$} & \multicolumn{4}{|c|}{2005} & \multicolumn{4}{c}{2014} \\
\cline { 2 - 8 } & \multicolumn{2}{|c|}{ Mulher } & \multicolumn{2}{c|}{ Homem } & \multicolumn{2}{c}{ Mulher } & \multicolumn{2}{c}{ Homem } \\
\cline { 2 - 9 } & Negra & $\begin{array}{c}\text { Não } \\
\text { negra }\end{array}$ & Negro & $\begin{array}{c}\text { Não } \\
\text { negro }\end{array}$ & Negra & $\begin{array}{c}\text { Não } \\
\text { negra }\end{array}$ & Negro & $\begin{array}{c}\text { Não } \\
\text { negro }\end{array}$ \\
\hline $\begin{array}{l}\text { Com Carteira } \\
\begin{array}{l}\text { Assinada } \\
\text { Sem Carteira }\end{array}\end{array}$ & 34,46 & 45,17 & 41,55 & 48,01 & 44,98 & 53,60 & 55,56 & 56,90 \\
Assinada & 65,54 & 54,83 & 58,45 & 51,99 & 55,02 & 46,40 & 44,44 & 43,10 \\
\hline
\end{tabular}

Fonte: elaborada pelos autores a partir das PNADs de 2005 e 2014.

A Tabela 4 revela uma outra face positiva da dinâmica do emprego no Nordeste, quando melhora a distribuição de trabalhadores em favor da categoria empregado com carteira. A formalização experimentada no mercado não é praticamente sentida para o caso dos trabalhadores domésticos, que em sua maioria ainda trabalha sem carteira assinada. A segunda categoria que mais ocupa trabalhadoras negras é a de domésticas sem carteira, que somada a outros empregados sem carteira perfaz um total de $28,88 \%$ das mulheres negras. Esse percentual praticamente se mantém para 2014.

Tabela 4 - Nordeste - Ocupação de mulheres e homens, negros e não negros, segundo posição na ocupação - 2005/2014 


\begin{tabular}{|c|c|c|c|c|c|c|c|c|}
\hline \multirow{3}{*}{$\begin{array}{l}\text { Posição na } \\
\text { ocupação }\end{array}$} & \multicolumn{4}{|c|}{2005} & \multicolumn{4}{|c|}{2014} \\
\hline & \multicolumn{2}{|c|}{ Mulher } & \multicolumn{2}{|c|}{ Homem } & \multicolumn{2}{|c|}{ Mulher } & \multicolumn{2}{|c|}{ Homem } \\
\hline & Negra & $\begin{array}{c}\text { Não } \\
\text { negra }\end{array}$ & Negro & $\begin{array}{c}\text { Não } \\
\text { negro }\end{array}$ & Negra & $\begin{array}{c}\text { Não } \\
\text { negra }\end{array}$ & Negro & $\begin{array}{l}\text { Não } \\
\text { negro }\end{array}$ \\
\hline $\begin{array}{l}\text { Empregado com } \\
\text { carteira }\end{array}$ & 12,62 & 18,71 & 19,43 & 21,62 & 20,06 & 25,87 & 29,29 & 28,95 \\
\hline Militar & 0,00 & 0,02 & 0,27 & 0,37 & 0,02 & 0,03 & 0,26 & 0,32 \\
\hline $\begin{array}{l}\text { Funcionário } \\
\text { público estatutário }\end{array}$ & 7,12 & 9,76 & 3,36 & 4,62 & 9,34 & 11,97 & 4,07 & 5,48 \\
\hline $\begin{array}{l}\text { Outros } \\
\text { empregados sem } \\
\text { carteira }\end{array}$ & 13,89 & 15,22 & 27,17 & 23,16 & 15,18 & 16,54 & 23,20 & 21,70 \\
\hline $\begin{array}{l}\text { Trabalhador } \\
\text { doméstico com } \\
\text { carteira }\end{array}$ & 2,04 & 1,53 & 0,30 & 0,19 & 2,45 & 1,95 & 0,26 & 0,19 \\
\hline $\begin{array}{l}\text { Trabalhador } \\
\text { doméstico sem } \\
\text { carteira }\end{array}$ & 14,00 & 9,35 & 0,59 & 0,47 & 12,36 & 7,54 & 0,43 & 0,37 \\
\hline Conta própria & 20,41 & 18,82 & 31,11 & 30,18 & 20,56 & 17,67 & 28,75 & 28,34 \\
\hline Empregador & 1,27 & 3,00 & 2,89 & 6,13 & 1,04 & 2,85 & 2,42 & 4,93 \\
\hline $\begin{array}{l}\text { Trabalhador na } \\
\text { produção para o } \\
\text { próprio consumo }\end{array}$ & 13,15 & 10,79 & 4,32 & 4,62 & 13,02 & 9,97 & 7,94 & 7,03 \\
\hline $\begin{array}{l}\text { Trabalhador na } \\
\text { construção para o } \\
\text { próprio uso }\end{array}$ & 0,07 & 0,02 & 0,26 & 0,10 & 0,02 & 0,00 & 0,18 & 0,08 \\
\hline Não-remunerado & 15,44 & 12,78 & 10,31 & 8,55 & 5,94 & 5,59 & 3,18 & 2,62 \\
\hline Total & 100 & 100 & 100 & 100 & 100 & 100 & 100 & 100 \\
\hline
\end{tabular}

Fonte: elaborada pelos autores a partir das PNADs de 2005 e 2014.

Chama atenção a concentração elevada da população que trabalha por conta própria, principalmente homens e mulheres não negras. A lógica dessas ocupações deve ser vista muito menos pela ótica de uma cultura empreendedora e muito mais pela desestruturação de parte do mercado menos dinâmico nacional e pela disputa dos melhores postos de trabalho por trabalhadores melhor qualificados, processo que força indivíduos em sua maioria à busca de garantias para sua sobrevivência, essencialmente ligadas à informalidade. Esse trabalhador atua no mercado por meio do uso intensivo de sua própria força laboral (CACCIAMALI, 2000), não dispõe de recursos para a melhor capitalização e para provisões em tecnologias que lhes garantam competitividade, além de estarem muito mais vulneráveis aos ciclos recessivos da economia doméstica. Se se considera a produção para o autoconsumo, a distribuição de trabalhadores nessas duas categorias revelam ocupações em sua maioria ligadas a forma de trabalho precárias e de baixa produtividade, faixas que se apresentam sem muitas alterações entre 2004 e 2014. No caso das mulheres negras, $13 \%$ destas trabalham apenas para o autoconsumo, mostrando grande vulnerabilidade desta população e que grandes são os desafios para a mudança desta situação, mesmo considerando uma década onde melhoram as condições do mercado de trabalho em geral (Tabela 4).

Os dados de escolaridade e remuneração constituem-se bons indicadores do perfil dos trabalhadores e trabalhadoras nordestinos. O fenômeno brasileiro de que a mulher apresenta em média mais anos de estudo que os homens se repete no 
Nordeste. Esse é um dos fatores apontados por Bruschini e Lombardi $(2003,2008)$ como responsável pelo ingresso e ascensão das mulheres no mercado de trabalho recente. As mulheres não negras são a parcela da população que apresenta as maiores médias de anos de estudo tanto em 2005, como em 2014. E os negros, homens e mulheres, tem menos anos de estudo nos dois anos analisados. Porém, uma certa tendência de convergência, não necessariamente confirmada em médio prazo, é constatada quando são as mulheres negras que mais melhoram sua média de estudo (variação de $0,44 \%$ ), seguida dos homens negros (variação de $0,41 \%$ ).

Tabela 5 - Nordeste - Ocupação de mulheres e homens, negros e não negros, segundo média de anos de estudo - 2005/2014

\begin{tabular}{l|c|c|c}
\hline \multicolumn{1}{c|}{ Segmentos } & $\mathbf{2 0 0 5}$ & $\mathbf{2 0 1 4}$ & Variação \\
\hline Mulher negra & 2,98 & 3,42 & 0,44 \\
Mulher não negra & 3,36 & 3,73 & 0,37 \\
Homem negro & 2,75 & 3,16 & 0,41 \\
Homem não negro & 3,15 & 3,52 & 0,37 \\
\hline
\end{tabular}

Fonte: elaborada pelos autores a partir das PNADs de 2005 e 2014.

A distribuição de trabalhadores e trabalhadoras por faixas que medem o número de anos de estudo é apresentada na Tabela 6. É possível constatar que parcela considerável da mão de obra regional ainda possui baixa escolaridade, com grande concentração nas faixas até 3 anos de estudo, o que representa severa restrição à absorção dessa população em empregos que exigem melhor qualificação e ofereçam maior remuneração. Contudo, essa concentração se reduz em todas as categorias consideradas, embora mais intensamente para homens negros (queda de 11,16\%) e mulheres negras (queda de 9,17\%). Em 2005, a faixa que mais concentrava a mão de obra nordestina era a de 4 a 7 anos de estudo, havendo, para 2014, uma melhor redistribuição em faixas com mais anos de estudo. Os trabalhadores mais escolarizados, que detém acima de 11 anos de estudo, aumentam entre 2005 e 2014, sendo as mulheres negras, novamente, a categoria que mais desloca mão de obra pra essas faixas de escolaridade.

Tabela 6 - Nordeste - Ocupação de mulheres e homens, negros e não negros, segundo anos de estudo - 2005/2014

\begin{tabular}{l|c|c|c|c|c|c|c|c}
\hline \multirow{2}{*}{ Anos de estudo } & \multicolumn{4}{c|}{2005} & \multicolumn{4}{c}{2014} \\
\cline { 2 - 9 } & \multicolumn{2}{|c|}{ Mulher } & \multicolumn{2}{c|}{ Homem } & \multicolumn{2}{c}{ Mulher } & \multicolumn{2}{c}{ Homem } \\
\cline { 2 - 9 } & Negra & $\begin{array}{c}\text { Não } \\
\text { negra }\end{array}$ & Negro & $\begin{array}{c}\text { Não } \\
\text { negro }\end{array}$ & Negra & $\begin{array}{c}\text { Não } \\
\text { negra }\end{array}$ & Negro & $\begin{array}{c}\text { Não } \\
\text { negro }\end{array}$ \\
\hline Sem instrução e menos & 18,98 & 14,80 & 21,84 & 16,86 & 14,83 & 11,62 & 17,39 & 13,67 \\
de 1 ano & 17,57 & 13,85 & 22,05 & 17,48 & 12,55 & 10,20 & 15,33 & 12,06 \\
1 a 3 anos & 31,12 & 27,55 & 30,21 & 27,99 & 24,98 & 23,19 & 27,94 & 25,21 \\
4 a 7 anos & 13,74 & 14,71 & 12,19 & 13,70 & 16,36 & 14,51 & 15,71 & 14,98 \\
8 a 10 anos & 16,47 & 22,58 & 12,29 & 19,17 & 25,89 & 29,50 & 20,46 & 26,12 \\
11 a 14 anos & 2,12 & 6,51 & 1,43 & 4,80 & 5,38 & 10,99 & 3,17 & 7,97 \\
Total anos ou mais & 100 & 100 & 100 & 100 & 100 & 100 & 100 & 100 \\
\hline
\end{tabular}

Fonte: elaborada pelos autores a partir das PNADs de 2005 e 2014. 
A análise da remuneração média no Nordeste repete o que já foi constatado no Brasil, que as mulheres, mesmo com maior escolaridade, auferem menores rendimentos do que os homens, apesar da tendência de redução do hiato salarial na economia brasileira (BANDEIRA; MELO; PINHEIRO, 2010; QUIRINO, 2012). Em 2005, na categoria negros, as mulheres ganhavam 35\% menos que os homens e entre não negros, as mulheres ganhavam a menos 30\%. Em 2014, essas diferenças se reduzem a $29,3 \%$ e $21 \%$, respectivamente (Tabela 7 ).

Relativo à evolução dos rendimentos, a política de valorização do salário mínimo se faz sentir na melhoria considerável dos rendimentos médios, ficando os melhores ganhos para as mulheres negras (81,05\%), seguidas dos homens negros (65,55\%). Porém, quando se consideram as segregações por raça e gênero, a diferença entre o pior rendimento (mulher negra) e o melhor rendimento (homem branco) aumenta de 38\%, em 2005, para 50,1\%, 2014, revelando o longo caminho a ser percorrido para a redução de vulnerabilidades históricas e correção de distorções que atingem por gerações o mercado de trabalho e a sociedade brasileira.

Tabela 7 - Nordeste - Ocupação de mulheres e homens, negros e não negros, segundo remuneração média em reais* - 2005/2014

\begin{tabular}{lcc|c|c}
\hline \multicolumn{1}{c|}{ Segmentos } & $\mathbf{2 0 0 5}$ & $\mathbf{2 0 1 4}$ & Variação \\
\hline Mulher negra & 380,44 & 688,81 & 81,05 \\
Mulher não negra & 699,47 & $1.084,46$ & 55,04 \\
Homem negro & 589,09 & 975,25 & 65,55 \\
Homem não negro & 997,79 & $1.376,01$ & 37,91 \\
\hline
\end{tabular}

Fonte: elaborada pelos autores a partir das PNADs de 2005 e 2014.

*Valores deflacionados com base no Índice Geral de Preços -

Disponibilidade Interna (IGP-DI), a preços de 2014.

Os dados da Tabela 8 revelam uma das faces mais brutais da precarização do trabalho no Brasil, aqui reproduzidos pelo Nordeste, que é o baixo salário auferido pela mão de obra. Em 2005, 95\% das mulheres negras recebiam até um salário mínimo, mulheres não negras, $88 \%$, homens negros, $92 \%$ e homens não negros, $82 \%$. Apesar de expressiva a redução do número de trabalhadores e trabalhadoras nessa faixa de remuneração no ano de 2014, a redistribuição ocorre basicamente em favor de ganhos salariais entre 1 e 2 SM. Em 2014, apenas 6,8\% das mulheres negras ganham entre 2 e $4 \mathrm{SM}$, enquanto para homens brancos esse percentual atinge $13,2 \%$. 
Tabela 8 - Nordeste - Ocupação de mulheres e homens, negros e não negros, segundo faixas de rendimento, em salários mínimos - 2005/2014

\begin{tabular}{|c|c|c|c|c|c|c|c|c|}
\hline \multirow{3}{*}{$\begin{array}{l}\text { Faixas de } \\
\text { rendimento }\end{array}$} & \multicolumn{4}{|c|}{2005} & \multicolumn{4}{|c|}{2014} \\
\hline & \multicolumn{2}{|c|}{ Mulher } & \multicolumn{2}{|c|}{ Homem } & \multicolumn{2}{|c|}{ Mulher } & \multicolumn{2}{|c|}{ Homem } \\
\hline & Negra & $\begin{array}{c}\text { Não } \\
\text { negra }\end{array}$ & Negro & $\begin{array}{c}\text { Não } \\
\text { negro }\end{array}$ & Negra & $\begin{array}{c}\text { Não } \\
\text { negra }\end{array}$ & Negro & $\begin{array}{c}\text { Não } \\
\text { negro }\end{array}$ \\
\hline de 0 a $1 / 2 S M$ & 85,54 & 72,91 & 74,77 & 63,07 & 41,25 & 30,83 & 27,30 & 23,00 \\
\hline de $1 / 2$ a $1 S M$ & 9,40 & 14,87 & 16,76 & 19,21 & 31,51 & 28,46 & 30,71 & 27,37 \\
\hline de 1 a 2 SM & 3,54 & 7,18 & 5,69 & 9,99 & 17,57 & 22,50 & 27,04 & 25,70 \\
\hline de 2 a $3 S M$ & 0,87 & 2,20 & 1,23 & 2,82 & 4,99 & 7,79 & 7,86 & 10,35 \\
\hline de 3 a 4 SM & 0,35 & 1,27 & 0,76 & 1,85 & 1,81 & 2,49 & 2,11 & 2,87 \\
\hline de 4 a 5 SM & 0,09 & 0,30 & 0,17 & 0,50 & 1,32 & 2,55 & 1,97 & 3,42 \\
\hline acima de $5 \mathrm{SM}$ & 0,21 & 1,26 & 0,63 & 2,56 & 1,55 & 5,37 & 3,01 & 7,30 \\
\hline Total & 100 & 100 & 100 & 100 & 100 & 100 & 100 & 100 \\
\hline
\end{tabular}

Fonte: elaborada pelos autores a partir das PNADs de 2005 e 2014.

\section{Considerações finais}

De modo geral, a melhoria das condições econômicas e do mercado de trabalho experimentada pelo Brasil, especialmente nos anos 2000, ampliam as oportunidades reservadas às mulheres e se estendem, embora de forma diferenciada, condicionando um novo padrão de inserção das mulheres negras no mercado de trabalho. Esse padrão é também em parte influenciado por uma mudança societária que traz, subjacente a uma maior valorização da mulher na sociedade, um conjunto de políticas afirmativas em benefício de grupos historicamente discriminados.

Apesar da melhoria inconteste de indicadores do mercado de trabalho da mulher negra no Nordeste, como o melhor ritmo de crescimento da população ocupada, queda mais intensa do desemprego, maior variação da média de anos de estudo, além de ganhos significativos de participação em melhores faixas de escolaridade, a face do desemprego e da informalidade ainda é negra e feminina. Ainda, se se acredita que só a qualidade das ocupações pode contribuir para a presença mais decente das mulheres negras nos espaços laborais e de sua permanência nos mesmos, a larga concentração destas em atividades com perfil mais degradante, com maior rotatividade e piores salários demonstram o longo caminho a ser percorrido em busca de políticas mais inclusivas e focalizadas para a eliminação e não apenas suavização de disparidades e segregações. Portanto, a consolidação e amplificação de medidas afirmativas podem se constituir num termômetro para mudanças mais estruturais nessa participação da mulher negra na economia e sociedade brasileiras, diminuindo a sua vulnerabilidade a tensões conjunturais.

Ressalta-se que as mudanças ocorridas a partir de 2016, subsequente à ruptura institucional e democrática, consubstanciadas na queda do governo de Dilma Rousself, ameaçam, de forma generalizada, os avanços obtidos no sentido de se reverteram as assimetrias históricas presentes no mercado de trabalho nacional.

Devem contribuir para isso a política macroeconômica de austeridade fiscal e monetária, as reformas institucionais em curso (previdenciária, tributária e 
administrativa, em nível federal, estadual e municipal), a inflexão na trajetória de expansão de gastos sociais, a indefinição quanto aos rumos de políticas setoriais, regionais, afirmativas e a necropolítica ${ }^{6}$ que atinge pobres, negros, mulheres, jovens e idosos. Tem-se, ainda, como agravante, a severa contração que devem experimentar as economias mundial e brasileira em 2020 e nos anos subsequentes, no cenário de pandemia global, associada à COVID-19, sendo essas populações as mais sensíveis aos cenários de austeridade e crise societária e econômica geral.

\section{REFERÊNCIAS}

ALVES, C. L. B. Responsabilidade socioambiental: uma avaliação do setor de cerâmica na Região Metropolitana do Cariri - Ceará. Tese (Doutorado em Desenvolvimento e Meio Ambiente) - Universidade Federal do Ceará, Fortaleza, 2017. Disponível em: http://www.repositorio.ufc.br/handle/riufc/23172. Acesso em: 02 dez out. 2020.

ALVES, C.L.B.; PAULO, E.M. Ceará: recortes de uma economia em transformação. Crato: RDS, 2014.

ALVES, C. L. B. et al. Mercado de trabalho e vulnerabilidade ocupacional na região metropolitana do Cariri. In: MORETTO, A. J. et al. (org.). As transformações no mundo do trabalho e o sistema público de emprego como instrumento de inclusão social. Fortaleza: IDT, 2018. p. 129-158. Disponível em:

http://www.idt.org.br/PortalIDT/Arquivos/Publicacoes/012_As_Transformacoes_no_ Mundo_do_Trabalho.pdf. Acesso em: 20 maio 2020.

ALVES, J. E. D. A transição demográfica e a janela de oportunidade. Blaudel Papers, São Paulo, v. 1, p. 1-13, 2008. Disponível em:

http://en.braudel.org.br/research/archive/downloads/a-transicao-demografico-e-ajanela-de-oportunidade.pdf. Acesso em: 20 maio 2020.

ARAUJO, V. L.; GENTIL, D. L. Avanços, recuos, acertos e erros: uma análise da resposta da política econômica brasileira à crise financeira internacional. Rio de Janeiro: IPEA, 2011. (Texto para discussão, n. 1602). Disponível em:

https://www.ipea.gov.br/portal/images/stories/PDFs/TDs/td_1602.pdf. Acesso em: 20 maio 2020.

BANDEIRA, L.; MELO, H. P.; PINHEIRO, L. S. Mulheres em dados: o que informa a PNAD/IBGE, 2008. Revista do Observatório Brasil da Igualdade de Gênero, ed. especial, Brasília, DF, p. 107-119, jul. 2010. Disponível em: http://www.observatoriodegenero.gov.br/menu/publicacoes/revista-doobservatorio-edicao-especial-tema-autonomia-economica-empoderamento-e-

\footnotetext{
${ }^{6}$ Caracterização usada por Mbembe (2018) referente às formas contemporâneas que subjugam a vida ao poder da morte.
} 
insercao-das-mulheres-no-mercado-de-trabalho-julho-2010/at_download/file. Acesso em: 20 maio 2020.

BARBOSA, N.; SOUZA, J. A. P. A inflexão do governo Lula: política econômica, crescimento e distribuição de renda. In: SADER, E.; GARCIA, M. A. (org.) Brasil: entre o passado e o futuro. São Paulo: Boitempo, 2010. p. 57-110.

BARBOSA, W. L. Cultura negra e dominação. Porto Alegre: Unisinos, 2002. (Coleção Aldus, v. 9).

BENTO, M. A. S. A mulher negra no mercado de trabalho. Revista Estudos Feministas, Florianópolis, v. 3, n. 2, 1995. Disponível em: https://periodicos.ufsc.br/index.php/ref/article/view/16466/15036. Acesso em: 11 nov. 2019.

BRASIL. [Constituição (1988)]. Constituição da República Federativa do Brasil de 1988. Diário Oficial [da] República Federativa do Brasil: seção 1, Brasília, DF, ano CXXVI, n. 191-A, p. 1, 5 out. 1988. Disponível em:

http://www.planalto.gov.br/ccivil_03/constituicao/constituicao.htm. Acesso em: 15 maio 2020.

BRASIL. Lei $n^{\circ} 10.639$, de 9 de janeiro de 2003. Altera a Lei no 9.394, de 20 de dezembro de 1996, que estabelece as diretrizes e bases da educação nacional, para incluir no currículo oficial da Rede de Ensino a obrigatoriedade da temática "História e Cultura Afro-Brasileira", e dá outras providências. Diário Oficial da União: seção 1, p. 1, 10 jan. 2003. Disponível em: http://www.planalto.gov.br/ccivil_03/leis/2003/l10.639.htm. Acesso em: 23 nov. 2019.

BRASIL. Lei ${ }^{\circ}$ 11.096, de 13 de janeiro de 2005. Institui o Programa Universidade para Todos - PROUNI, regula a atuação de entidades beneficentes de assistência social no ensino superior; altera a Lei $n^{\circ} 10.891$, de 9 de julho de 2004, e dá outras providências. Diário Oficial da União: seção, Brasília, DF, p. 7, 14 jan. 2005. Disponível em: http://www.planalto.gov.br/ccivil_03/_ato20042006/2005/lei/l11096.htm. Acesso em: 23 nov. 2019.

BRASIL. Lei $n^{\circ} 12.288$, de 20 de julho de 2010. Institui o Estatuto da Igualdade Racial; altera as Leis $\mathrm{n}^{\circ} 7.716$, de 5 de janeiro de 1989, 9.029, de 13 de abril de 1995, 7.347, de 24 de julho de 1985, e 10.778, de 24 de novembro de 2003. Diário Oficial da União: seção 1, Brasília, DF, p. 1, 21 jul. 2010. Disponível em: http://www.planalto.gov.br/ccivil_03/_Ato2007-2010/2010/Lei/L12288.htm. Acesso em: 23 nov. 2019.

BRASIL. Lei $n^{\circ} 12.711$, de 29 de agosto de 2012. Dispõe sobre o ingresso nas universidades federais e nas instituições federais de ensino técnico de nível médio e dá outras providências. 2012. Diário Oficial da União: seção 1, p. 1, 30 ago. 2012. 
Disponível em: http://www.planalto.gov.br/ccivil_03/_ato20112014/2012/lei/l12711.htm. Acesso em: 23 nov. 2019.

BRASIL. Lei $n^{\circ} 7.716$, de 5 de janeiro de 1989. Define os crimes resultantes de preconceito de raça ou de cor. Diário Oficial da União: seção 1, Brasília, DF, p. 369, 6 jan. 1989. Disponível em: http://www.planalto.gov.br/ccivil_03/leis/l7716.htm. Acesso em: 15 maio 2020.

BRASIL. Lei $n^{\circ} 9.459$, de 13 de maio de 1997 . Altera os arts. $1^{\circ}$ e 20 da Lei $n^{\circ} 7.716$, de 5 de janeiro de 1989, que define os crimes resultantes de preconceito de raça ou de cor, e acrescenta parágrafo ao art. 140 do Decreto-lei $\mathrm{n}^{\circ} 2.848$, de 7 de dezembro de 1940. Diário Oficial da União: seção 1, Brasília, DF, p. 9901, 14 maio 1997. Disponível em: http://www.planalto.gov.br/ccivil_03/leis/l9459.htm. Acesso em: 15 maio 2020.

BRITO, F. Transição demográfica e desigualdades sociais no Brasil. Revista Brasileira de Estudos Populacionais, São Paulo, v. 25, n. 1, p. 5-26, jan./jun. 2008. Disponível em: https://www.scielo.br/pdf/rbepop/v25n1/v25n1a02.pdf. Acesso em: 20 maio 2020.

BRUSCHINI, C.; LOMBARDI, M. R. Mulheres e homens no mercado de trabalho brasileiro: um retrato dos anos 1990. In: MARUANI, M.; HIRATA, H. As novas fronteiras da desigualdade: homens e mulheres no mercado de trabalho. São Paulo: SENAC, 2003.

BRUSCHINI, C.; LOMBARDI, M. R. Trabalho, educação e rendimento das mulheres no Brasil em anos recentes. In: HIRATA, H.; SEGNINI, L. (org.). Organização, trabalho e gênero. São Paulo: Editora Senac, 2008.

BRUSCHINI, C.; LOMBARDI, M. R. Trabalhadoras brasileiras dos anos 90: mais numerosas, mais velhas e mais instruídas. Mulher e Trabalho, v.2, 2011. Disponível em:

https://revistas.fee.tche.br/index.php/mulheretrabalho/article/download/2681/3003. Acesso em: dez.2020.

CACCIAMALI, M. C. Globalização e processo de informalidade. Economia e Sociedade, Campinas, n. 14, p. 153-174, jun. 2000. Disponível em: http://www.eco.unicamp.br/images/arquivos/artigos/507/06-Cacciamali.pdf. Acesso em: 20 maio 2020.

CARNEIRO, D.D.; MODIANO, E.M. Ajuste externo e desequilíbrio interno. In: ABREU, M. de P. (org.). A ordem do progresso. Dois séculos de política econômica no Brasil. 2. ed. Rio de Janeiro: Elsevier, 2014.

COUTINHO, L.; BALTAR, P.; CAMARGO, F. Desempenho industrial e emprego sob a política de estabilização. In: ORGANIZAÇÃO INTERNACIONAL DO TRABALHO. Brasil: abertura e ajuste do mercado de trabalho no Brasil. São Paulo: Editora 34, 1999. 
DAVIS, A. Mulheres, raça e classe. São Paulo: Boitempo, 2016.

DIEESE. A mulher negra no mercado de trabalho metropolitano: inserção marcada pela dupla discriminação. Estudos e pesquisas, São Paulo, ano II, n. 14, nov. 2005. Disponível em:

https://www.dieese.org.br/estudosepesquisas/2005/estpesq14112005_mulhernegra. pdf. Acesso em: 29 out. 2018.

DINIZ, C.C. Dinâmica regional da economia brasileira e suas perspectivas. Brasília: IPEA, 1995. (Texto para discussão n 375).

FERREIRA, Maria de Fátima Silveira; LEMOS, Mauro Borges. Localização industrial e fatos estilizados da nova reconfiguração espacial do Nordeste. Revista Econômica do Nordeste, Fortaleza, v.31, n. especial, p. 484-507, nov. 2000.

GARCIA, P. P. Análise das ações afirmativas à luz do princípio da igualdade. Revista Jus Navigandi, Teresina, n. 3160, 25 fev. 2012.

GENTIL, D.; HERMANN, J. A política fiscal do primeiro governo Dilma Rousseff: ortodoxia e retrocesso. Economia e Sociedade, Campinas, v. 26, n. 3, p. 793-816, dez. 2017. Disponível em: https://www.scielo.br/pdf/ecos/v26n3/1982-3533-ecos-2603-793.pdf. Acesso em: 20 maio 2020.

GUIMARÃES NETO, L. Desconcentração espacial regional da economia brasileira. Formas de desconcentração e fatores determinantes. João Pessoa: CME/UFPB, 1994. (Texto para discussão $n^{\circ} 80$ ).

HIRATA, H. Mudanças e permanências nas desigualdades de gênero: divisão sexual do trabalho numa perspectiva comparativa. Friedrich Ebert Stiftung Brasil, $n^{\circ} 7$. 2015.

IBGE. Sistema IBGE de Recuperação Automática - SIDRA: banco de tabelas estatísticas. Rio de Janeiro: IBGE, 2019. Disponível em:

https://sidra.ibge.gov.br/home/ipca15/brasil. Acesso em: 20 maio 2020.

LEONE, E. T.; BALTAR, P. A mulher na recuperação recente do mercado de trabalho brasileiro. Revista Brasileira de Estudos Populacionais, São Paulo, v. 25, n. 2, p. 233249, jul./dez. 2008. Disponível em:

https://www.scielo.br/pdf/rbepop/v25n2/v25n2a03.pdf. Acesso em: 20 maio 2020.

LIMA, M.; RIOS, F.; FRANÇA, D. Articulando gênero e raça: a participação das mulheres negras no mercado de trabalho (1995-2009). In: MARCONDES, M. M. et al. (org.). Dossiê mulheres negras: retrato das condições de vida das mulheres negras no Brasil. Brasília, DF: IPEA, 2013. p. 53-80. Disponível em:

https://www.ipea.gov.br/portal/images/stories/PDFs/livros/livros/livro_dossie_mulhe res_negras.pdf. Acesso em: 25 ago. 2018. 
LOPES, K.; LUCILVO FILHO; LIMA, L. C. Emprego doméstico: evolução ou precarização? Uma comparação dos anos de 2004 e 2014. In: ENCONTRO NACIONAL DA ASSOCIAÇÃO BRASILEIRA DE ESTUDOS POPULACIONAIS, 20., 2016, PoçOs de Caldas. Anais eletrônicos [... ]. Poços de Caldas: ABEP, 2016. Disponível em: http://abep.org.br/xxencontro/files/paper/1027-809.pdf. Acesso em: 20 maio 2020.

MARTINS, S. S. Direito e combate à discriminação nacional no Brasil. In: HUTLEY, L.; GUIMARÃES, A. S. A (org.). Tirando a máscara: ensaios sobre o racismo no Brasil. São Paulo: Paz e Terra, 2000.

MBEMBE, A. Necropolítica. N-1 Edições, 2018.

MUNANGA, K.; GOMES, N. L. O negro no Brasil de hoje. São Paulo: Global, 2006.

NERI, M. C.; CAMARGO, J. M.; REIS, M. C. Mercado de trabalho nos anos 90: fatos estilizados e interpretações. Rio de Janeiro: IPEA, 2000. (Texto para discussão, n. 743). Disponível em:

https://www.ipea.gov.br/portal/images/stories/PDFs/TDs/td_0743.pdf. Acesso em: 20 maio 2020.

NOGUEIRA, B. I. Significações do corpo negro. 1998. 146 f. Tese (Doutorado em Psicologia) — Universidade de São Paulo, São Paulo, 1998. Disponível em: www.ammapsique.org.br/baixe/corpo-negro.pdf. Acesso em: 22 out. 2018.

OLIVEIRA, M. F. A política externa brasileira no governo Lula (2003-2010): um exercício de autonomia pela assertividade. In: ENCONTRO DA ABCP, 9., 2014, Brasília, DF. Anais eletrônicos [... ]. Brasília, DF: ABCP, 2014. Disponível em: https://cienciapolitica.org.br/index.php/system/files/documentos/eventos/2017/03/p olitica-externa-brasileira-governo-lula-2003-2010-exercicio.pdf. Acesso em: 20 maio 2020.

PACHECO, C. A. Fragmentação da nação. Campinas: UNICAMP/IE, 1998.

PEREIRA, B. P. De escravas a empregadas domésticas: a dimensão social e o "lugar" das mulheres negras no pós-abolição. In: SIMPÓSIO NACIONAL DE HISTÓRIA ANPUH: 50 ANOS, 26., 2011, São Paulo. Anais eletrônicos [... ]. São Paulo: ANPUHSP, 2011. Disponível em: http://www.snh2011.anpuh.org/resources/anais/14/1308183602_ARQUIVO_ArtigoAN PUH-Bergman.pdf. Acesso em: 1 mar. 2019.

QUIRINO, R. Trabalho da mulher no Brasil nos últimos 40 anos. Revista Tecnologia e Sociedade, Curitiba, v. 8, n. 15, p. 90-102, 2002. Disponível em: https://periodicos.utfpr.edu.br/rts/article/view/2596/1693. Acesso em: 20 maio 2020.

RODRIGUES, A. da S.; ALVES, C.L.B.; PAULO, E.M. Trajetória recente dos gastos sociais e da pobreza no estado da Bahia: considerações para o período de 20032009. Bahia Análise \& Dados, v.22, n.1, p. 205-223, jan./mar. 2012. 
TRIPPIA, L. M.; BARACAT, E. M. A discriminação da mulher negra no mercado de trabalho e as políticas públicas. Revista eletrônica [do] Tribunal Regional do

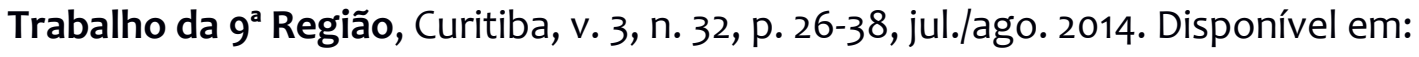
https://hdl.handle.net/20.500.12178/94254. Acesso em: 20 out. 2018.

VENTURI, A.; MATTEI, L. Mudança no mercado de trabalho e a condição da inserção da mulher catarinense. In: ENCONTRO DE ECONOMIA CATARINESE, 2., 2008, Chapecó. Anais eletrônicos [... ]. Chapecó: [s.n.], 2008. p. 684-702. Disponível em: https://necat.ufsc.br/files/2011/10/Lauro-2008.pdf. Acesso em: 17 abr. 2019.

VIEIRA, B. Mulheres negras no mercado de trabalho brasileiro: um balanço das políticas públicas. In: SEMINÁRIO INTERNACIONAL FAZENDO GÊNERO, 2017, Florianópolis. Anais eletrônicos [... ]. Florianópolis: [s.n.], 2017. p. 1-19. Disponível em:

http://www.en.wwc2017.eventos.dype.com.br/resources/anais/1499353872_ARQUIV O_Mulheresnegrasnomercadodetrabalhobrasileiro.pdf. Acesso em: 30 set. 2018.

Christiane Luci Bezerra Alves. Doutora em Desenvolvimento e Meio Ambiente pelo Programa de Pós-Graduação em Desenvolvimento e Meio Ambiente da Universidade Federal do Ceará (PRODEMA/UFC). Professora Associada do Departamento de Economia da Universidade Regional do Cariri (URCA). Pesquisadora do Laboratório de Estudos Interdisciplinares em Meio Ambiente, Território, Trabalho e Sustentabilidade - MATTAS. Rua Padre Arnaldo de Melo, 375 - Sossego - Crato - Ceará - Brasil. chrisluci@gmail.com

Jaqueline Kelândia Ferreira Alencar. Economista pela Universidade Regional do Cariri (URCA). Pesquisadora do Laboratório de Estudos Interdisciplinares em Meio Ambiente, Território, Trabalho e Sustentabilidade - MATTAS. Rua Cel. Antonio Luiz, 1161 - Pimenta - Crato - Ceará - Brasil (Departamento de Economia).xaquelinekelandia@gmail.com

Valéria Feitosa Pinheiro. Doutoranda em Economia pelo Dinter da Universidade Federal Fluminense-UFF/Universidade Regional do Cariri URCA. Professora Adjunta do Departamento de Economia da Universidade Regional do Cariri (URCA). Líder do Laboratório de Estudos Interdisciplinares em Meio Ambiente, Território, Trabalho e Sustentabilidade - MATTAS. Rua Sinobilina Peixoto de Carvalho, 102 - Coqueiro - Crato - Ceará - Brasil. valeriafp73@gmail.com

João Luís do Nascimento Mota. Doutor em Direito Econômico e Socioambiental pela Pontifícia Universidade Católica do Paraná (PUCPR), Professor Associado do Departamento de Economia da URCA. Rua Cel. Antonio Luiz, 1161 - Pimenta - Crato - Ceará - Brasil (Departamento de Economia).mota.joao@urca.br 
Como citar: ALVES, Christiane Luci Bezerra et al. Padrão de inserção da mulher negra no mercado de trabalho nordestino: notas para o período 2005-2014. Redes (St. Cruz Sul, Online), Santa Cruz do Sul, v. 25, p. 2713-2736, 2020. ISSN 1982-6745. doi:https://doi.org/10.17058/redes.v25io.15382.

\section{CONTRIBUIÇÃO DE CADA AUTOR}

\section{Christiane Luci Bezerra Alves}

Conceituação (Conceptualization)

Curadoria de Dados (Data curation)

Análise Formal (Formal analysis)

Metodologia (Methodology)

Escrita - Primeira Redação (Writing - original draft)

Escrita - Revisão e Edição (Writing - review \& editing).

\section{Jaqueline Kelândia Ferreira Alencar}

Conceituação (Conceptualization)

Análise Formal (Formal analysis)

Investigação/Pesquisa (Investigation)

Escrita - Primeira Redação (Writing - original draft)

\section{Valéria Feitosa Pinheiro}

Conceituação (Conceptualization)

Curadoria de Dados (Data curation)

Análise Formal (Formal analysis)

Investigação/Pesquisa (Investigation)

Supervisão/orientação (Supervision)

Escrita - Primeira Redação (Writing - original draft)

João Luís do Nascimento Mota

Análise Formal (Formal analysis)

Escrita - Primeira Redação (Writing - original draft)

Fontes de financiamento: não se aplica 